\title{
In Vitro Bulblet Induction from Shoot Apices of Lilium japonicum
}

K. Maesato ${ }^{1}$, K.S. Sarma ${ }^{2}$, H. Fukui ${ }^{3}$, and T. Hara
Faculty of Agriculture, Gifu University, Gifi 501-1.1, Japan

Additional index words. bulblet regeneration, micropropagation

Lilium japonicum Thunb., pink lily or lovely lily, is mainly grown in central Japan for use in religious ceremonies and as an ornamental. The wild population of $L$. japonicum is decreasing, and we are trying to revive its. cultivation using plant tissue culture techniques. Only a report by Shoyama et al. (1988) details work on L. japonicum. Although lilies usually are propagated by scaling, a technique that produces bulblets from each bulb scale, depending on the cultivar, other organs of lily plants have regenerative capacity, e.g., leaves (Niimi and Onazawa, 1979), peduncles and petals (Takayama and Misawa, 1979); and bulblets (Shoyama et al., 1988). Shoot apices have been used as explants for bulblet regeneration (Sheridan, 1968); however, the bulblets regenerated from callus may have undergone

Received for publication 7 Dec. 1989. The cost of publishing this paper was defrayed in part by the payment of page charges. Under postal regulations, this paper therefore must be hereby marked advertisement solely to indicate this fact.

${ }^{1}$ K. Maesato: Murakashi Lime Industry Co., 1-10 Miyashitacho, Aso-gun, Tochigi 327-05, Japan. ${ }^{2}$ K.S. Sarma; Biotechnology Dept., School of Biological Sciences, Madurai Kamaraj Univ., Madurai 625021, India.

${ }^{3}$ Horticulture Laboratory.

${ }^{4}$ Biotechnology Laboratory. chromosomal changes (Bayliss, 1980). We report direct bulblet initiation from shoot apex explants. Since shoot apices are not affected by viruses, the resultant bulblets likely would be healthy.

Shoot apices were excised from in vitrogrown bulblets and individually aseptically planted on Murashige and Skoog (1962) medium supplemented with $3 \%$ sucrose, 2,4dichlorophenoxy acetic acid (2,4-D) and naphthaleneacetic acid (NAA) (Table 1). The $\mathrm{pH}$ of the medium was adjusted to 5.8 before autoclaving and gelled with $0.7 \%$ Difco Bacto agar. The cultures were maintained at $20 \mathrm{C}$. After 55 to 60 days, the cultures were scored for regeneration, and results were subjected to statistical variance analysis.

The maximum frequency of bulblets was observed in medium containing no hormones (Table 1). With increasing hormone concentrations the frequency of bulblet formation gradually decreased with a concomitant increase in abnormal bulblets. Addition of hormone(s) is unnecessary to induce bulblets at high frequency. The lowest concentrations of 2,4-D and the two lower ones of NAA favored rooted bulblets, while the highest concentration of NAA, but not of 2,4-D, induced bulblets with roots and leaves just like the control (Table 1). The latter type of bulblets established themselves much faster in soil than those without leaves. These results clearly show that not only bulb scales but
Table 1. Effect of 2,4-D and NAA on bulblet induction from shoot apex explants of $L$. japonicum.

\begin{tabular}{|c|c|c|c|c|c|}
\hline \multirow[b]{3}{*}{$\begin{array}{c}\text { Treatmen } \\
(\mu \mathrm{M})\end{array}$} & & \multicolumn{4}{|c|}{ Bulblets produced (\%) } \\
\hline & & \multicolumn{3}{|c|}{ Normal } & \multirow[b]{2}{*}{ Abnormal } \\
\hline & & Total & Roots & $\begin{array}{c}\text { Roots \& } \\
\text { leaves }\end{array}$ & \\
\hline Control & & 67 & 43 & 57 & 20 \\
\hline \multirow[t]{3}{*}{$2,4-\mathrm{D}$} & 2.26 & 53 & 67 & 33 & 47 \\
\hline & 5.52 & 33 & 40 & 60 & 60 \\
\hline & 9.05 & 0 & 0 & 0 & 100 \\
\hline $\mathrm{LSD}^{\mathrm{z}}$ & & 26 & & & 25 \\
\hline Control & & 67 & 43 & 57 & 20 \\
\hline \multirow[t]{3}{*}{ NAA } & 2.68 & 53 & 100 & 0 & 33 \\
\hline & 5.36 & 33 & 100 & 0 & 60 \\
\hline & 10.72 & 13 & 40 & 60 & 60 \\
\hline $\operatorname{LSD}^{z}$ & & 27 & & & 28 \\
\hline
\end{tabular}

${ }^{2} \mathrm{~F}$ test showed that there was a significant difference between treatment plots, and the least significant difference (LsD) was calculated.

also shoot apices can be used as explants for micropropagating L. japonicum.

\section{Literature Cited}

Bayliss, M.W. 1980. Chromosomal variation in plant tissue culture in culture. Intl. Rev. Cytol. (Suppl.) 11A:113-144.

Murashige, T. and F. Skoog. 1962. A revised medium for rapid growth and bioassays with tobacco tissue cultures. Physiol. Plant. 15:473497.

Niimi, Y. and T. Onazawa. 1979. In vitro bulblet formation from leaf segments of lilies, especially Lilium rebellum Baker. Scientia Hort. 11:379-389.

Sheridan, W.F. 1968. Tissue culture of the monocot Lilium. Planta 82:189-192.

Shoyama, Y., N. Hasegawa, and L Nishioka. 1988. In vitro propagation of Lilium japonicum by culture of bulblets. Shoyakugaku. Zasshi 41:352355.

Takayama, S. and M. Misawa. 1979. Differentiation in Lilium bulb scales grown in vitro. Effect of various cultural conditions. Physiol. Plant. 46:184-190. 